\title{
The neurosurgery residency interview: assessing applicant perspectives on question content, utility, and stress
}

\author{
Scott L. Zuckerman, MD, MPH, ${ }^{1}$ Natalie Limoges, DO, ${ }^{2}$ Aaron M. Yengo-Kahn, MD, ${ }^{1}$ \\ Christopher S. Graffeo, MD, MS, ${ }^{3}$ Lola B. Chambless, MD, ${ }^{1}$ Rohan Chitale, MD, ${ }^{1}$ J Mocco, MD, MS, ${ }^{4}$ \\ and Susan Durham, MD²
}

\begin{abstract}
${ }^{1}$ Department of Neurological Surgery, Vanderbilt University Medical Center, Nashville, Tennessee; 'Division of Neurosurgery, University of Vermont Medical Center, Burlington, Vermont; ${ }^{3}$ Department of Neurosurgery, Mayo Clinic, Rochester, Minnesota; and ${ }^{4}$ Department of Neurosurgery, Mount Sinai School of Medicine, New York, New York
\end{abstract}

\begin{abstract}
OBJECTIVE Residency interviews are integral to the recruitment process yet imperfect. Through surveys of neurosurgery residency applicants, the authors describe interview content and the perceived utility and stress of topics from the applicant's perspective.
\end{abstract}

METHODS All 2018-2019 neurosurgery resident applicants applying to three particular programs were surveyed. Across 10 interview topics, survey questions assessed topic frequency and the applicant's opinion of the utility and stress of each topic (Likert scale 1-5). Analyses included descriptive statistics, Spearman's rank correlation, and logistic regression.

RESULTS One hundred thirty-three of 265 surveyed US residency applicants (50\%) responded. Extracurricular activities, research, future career, non-medicine interests, and small talk were discussed in all interviews. The least frequent topics included neurosurgical knowledge assessment $(79 \%)$ and manual dexterity tests (45\%). The most useful topics according to respondents were future career objectives $(4.78 \pm 0.49)$ and prior research $(4.76 \pm 0.50)$; the least useful were neurosurgical knowledge assessment $(2.67 \pm 1.09)$ and manual dexterity tests $(2.95 \pm 1.05)$. The most stressful topics were neurosurgical knowledge assessment $(3.66 \pm 1.23)$ and ethical/behavioral scenarios $(2.94 \pm 1.28)$. The utility and stress of manual dexterity tests and neurosurgical knowledge assessments were inversely correlated $(r=-0.40$, $p<0.01 ; r=-0.36, p<0.01)$, whereas no such correlation existed for ethical/behavioral questions $(r=-0.12, p=0.18)$, indicating that ethical/behavioral questions may have been stressful but were potentially useful topics. Respondents who attended $\geq 15$ interviews were more likely to be asked about the three most stressful topics (each $p<0.05$ ). Respondents with children were less likely to be asked about ethical/behavioral scenarios (OR $0.13,95 \% \mathrm{Cl} 0.03-0.52, p<$ 0.01).

CONCLUSIONS Applicants found several of the most frequently discussed topics to be less useful, indicating a potential disconnect between applicant opinion and the faculty's preferred questions. Ethical/behavioral scenarios were rated as stressful but still useful, representing a potentially worthwhile type of question. These data provide several avenues for potential standardization and improvement of the interview process.

https://thejns.org/doi/abs/10.3171/2020.4.JNS2046

KEYWORDS education; recruitment; residency; behavioral interviews

$\mathrm{R}$ ECRUITMENT of neurosurgery residents is a fundamental responsibility of academic neurosurgery departments. Ensuring that we train competent, high-integrity surgeons maintains the future of our specialty. Amid a long and complex selection process, faculty across several specialties have identified the in-person interview as the most important factor in determining final selection. ${ }^{1,2}$ Applicants have confirmed the importance of interview day. ${ }^{3,4}$ Conversations with the program director and faculty have been rated as the most important aspect of interviews by $>90 \%$ of applicants, second only to meeting the residents. ${ }^{3-5}$

Despite its undisputed importance, the interview is far from perfect. Interviews have been found to be variable in duration and style, with the potential to create an unlevel playing field through unconscious bias, even leading 
to illegal questions. ${ }^{1,6,7}$ Unstructured interviews filled with small talk can result in subjective, unhelpful evaluations with poor interrater agreement. ${ }^{6}$ Faculty ratings also depend heavily on qualities of the interviewer; for example, more experienced, older faculty have been shown to provide lower applicant ratings. ${ }^{8}, 9$

Interviews also require considerable investment on the part of the program and applicant. Surveys of residency programs have reported median total recruitment costs of $\$ 148,000$ per program..$^{10}$ The average neurosurgery applicant interviews at 15 programs with median costs of $\$ 10,000.11,12$ Considering the investment of personnel, time, and money, it behooves the entire neurosurgical community to scrutinize the in-person interview in a way that allows applicants to familiarize themselves with programs and for programs to gather critical information about applicants. In its current state, the interview appears to be more about an ill-defined "fit" than a rigorously studied tenet of recruitment. ${ }^{13}$ Before this process can evolve, further information is needed about the content and perceptions of the interview.

Given the importance and heterogeneity of neurosurgery residency interviews, we aimed to address this topic from the applicant's perspective. Through surveys to US neurosurgery residency applicants, we sought to 1) describe interview content by topic frequency as well as the perceived utility and stress of each topic, 2) report associations between applicant characteristics and an increased likelihood of identifying questions as stressful, and 3) discern whether certain applicant characteristics are associated with an increased likelihood of being asked stressful questions.

\section{Methods \\ Study Design}

We conducted a cross-sectional, survey-based study of neurosurgery residency applicants from 2018 to 2019. Institutional review board exemptions were obtained prior to study initiation at all institutions.

\section{Population}

All 2018-2019 US neurosurgery resident applicants to three geographically diverse programs were anonymously surveyed $(n=265)$, a subset $(85 \%)$ of the larger pool of 312 total applicants that year. ${ }^{14}$ De-identified email lists to the following three programs were used: The University of Vermont, Vanderbilt University, and Cleveland Clinic. Duplicate email addresses were removed.

\section{Survey}

The survey was created based on prior literature ${ }^{6-8,11}$, ${ }^{15-17}$ and the anecdotal experience of all authors, and thus had not been previously used, nor validated. Question topics were chosen by consensus among several of the authors based on anecdotal interview experience. Of note, though the topic of "family" is illegal if asked about invasively or in terms of one's desire to have a future family, an applicant's upbringing and family background often naturally arise in conversation, which is why the topic was included in the survey. The survey was electronically ad- ministered and included 50 questions focused on applicant demographics and interview questions (Appendix 1). The following statement was included at the beginning of the survey: "When answering the following questions, please answer in the context of the interview setting, where the interviewer specifically asked questions regarding information that was not previously known or available on your application."

Survey questions dealt with how useful/appropriate or how stressful/anxiety provoking certain interview question topics were. For simplicity, these categories will hereafter be referred to as "useful" and "stressful," respectively, without their attached qualifiers. Neither term was specifically defined for the respondent. However, "useful" was meant to be broadly interpreted as questions the applicant found worthwhile for the program to learn more about them as a person and future trainee. "Stressful" was meant to be broadly interpreted as questions that elicited feelings of anxiety, discomfort, and uneasiness. In addition to demographic and personal information, the following questions were asked: 1) Did your interviews include discussion of the following topics? (yes/no), 2) How useful/appropriate were the following questions asked during your neurosurgical interviews? (Likert scale 1-5, $1=$ not useful/very inappropriate, 5 = very useful/appropriate), 3 ) How stressful/anxiety provoking were the following questions during your neurosurgical interviews? (Likert scale $1-5,1=$ no stress or anxiety, $5=$ very stressful).

Applicants were emailed from personal academic accounts and blind carbon copied for anonymity. Respondents could not see other applicant email addresses, and all survey responses were de-identified to the survey team. Three separate email invitations were sent to optimize participation. At the beginning of the survey, applicants were reassured of anonymity in their responses and encouraged to answer honestly and fully. To minimize any perceived concern over rank list order, changing opinions based on match results, or anonymity, surveys opened after applicant rank list submission and closed before match results.

\section{Statistical Analysis}

All continuous data were presented as the mean \pm standard deviation and/or median (range), whereas all count data were presented as number (\%). Likert variables were coded from 1 to 5 , according to increasing level of stress and utility. Likert variables were also collapsed to binary form, where $1-3=$ not useful/stressful and $4-5=$ useful/stressful. Spearman rank correlation was used to assess the relationship between responses. Univariate logistic regression was used to predict 1) who found specific interview question topics stressful, and 2) who would be asked specific questions. All statistical analyses were performed in Stata version 14 (StataCorp LLC). A p $\leq 0.05$ was considered statistically significant.

\section{Results \\ Demographics and Topics Asked}

A total of 133 of 265 surveyed US residency applicants $(50 \%)$ responded to the survey (Table 1$)$. Of the respon- 
TABLE 1. Demographics of 133 residency applicants

\begin{tabular}{|c|c|}
\hline Variable & No. $(\%)$ \\
\hline \multicolumn{2}{|l|}{ Age in yrs } \\
\hline $21-25$ & $35(26)$ \\
\hline $26-30$ & $89(67)$ \\
\hline $31-35$ & $8(6)$ \\
\hline $36-40$ & $1(1)$ \\
\hline \multicolumn{2}{|l|}{ Sex ${ }^{*}$} \\
\hline Male & $91(69)$ \\
\hline Female & $41(31)$ \\
\hline \multicolumn{2}{|l|}{ Race } \\
\hline White & $80(60)$ \\
\hline Asian & $31(23)$ \\
\hline Black & $9(7)$ \\
\hline Hispanic & $5(4)$ \\
\hline Multiple & $8(6)$ \\
\hline Foreign born & $28(21)$ \\
\hline Currently raising children & $13(10)$ \\
\hline \multicolumn{2}{|l|}{ Relationship } \\
\hline Single, never married & $69(52)$ \\
\hline Single, but cohabiting & $27(20)$ \\
\hline Married & $32(24)$ \\
\hline Divorced & $4(3)$ \\
\hline Widowed & $1(1)$ \\
\hline \multicolumn{2}{|l|}{ Interviews attended } \\
\hline$<5$ & $7(5)$ \\
\hline $5-9$ & $13(10)$ \\
\hline $10-14$ & $36(27)$ \\
\hline $15-19$ & $49(37)$ \\
\hline$\geq 20$ & $28(21)$ \\
\hline
\end{tabular}

* Data missing for one respondent $(n=132)$. dents, males represented a majority (69\%), $24 \%$ were married, and $10 \%$ had children. The majority of respondents (64\%) attended 10-19 interviews. All applicants reported being asked about the following topics during their interviews: extracurricular activities (including volunteering and leadership activities in medical school), prior research, future career objectives, and non-medicine interests (Fig. 1). Small talk also occurred in almost all respondent interviews (99\%). The least frequent topics were neurosurgical knowledge assessment (79\%) and manual dexterity test (45\%). An important note is that our sample of $31 \%$ women was similar to and thus representative of the entire application pool, in which $30 \%$ of the applicants were women. ${ }^{14}$

\section{Topics Most Useful and Stressful}

Mean scores for each topic are listed in Table 2. The topics rated most useful are presented in descending order of utility in Fig. 2. The most useful topics were as follows: future career objectives $(4.78 \pm 0.49)$, prior research $(4.76$ $\pm 0.50)$, and non-medicine interests $(4.46 \pm 0.71)$. The least useful questions were neurosurgical knowledge assessment $(2.67 \pm 1.09)$, manual dexterity tests $(2.95 \pm 1.05)$, and family $(3.51 \pm 0.95)$.

Topics are rated in descending order of stressfulness in Fig. 3. The most stressful topics were as follows: neurosurgical knowledge assessment $(3.66 \pm 1.23)$, ethical/behavioral scenarios $(2.94 \pm 1.28)$, and manual dexterity tests $(2.91 \pm 1.21)$. The least stressful topics were non-medicine interests/hobbies (1.38 \pm 0.72$)$, employment/volunteering $(1.48 \pm 0.71)$, and extracurricular activities $(1.50 \pm 0.76)$. The following topics were found to have the highest level of stress when the Likert scores were collapsed into binary responses $(1-3=$ not stressful, $4-5=$ stressful): neurosurgical knowledge assessment (59\%), ethical/behavioral

\section{Percentage of topics asked during neurosurgery interviews}

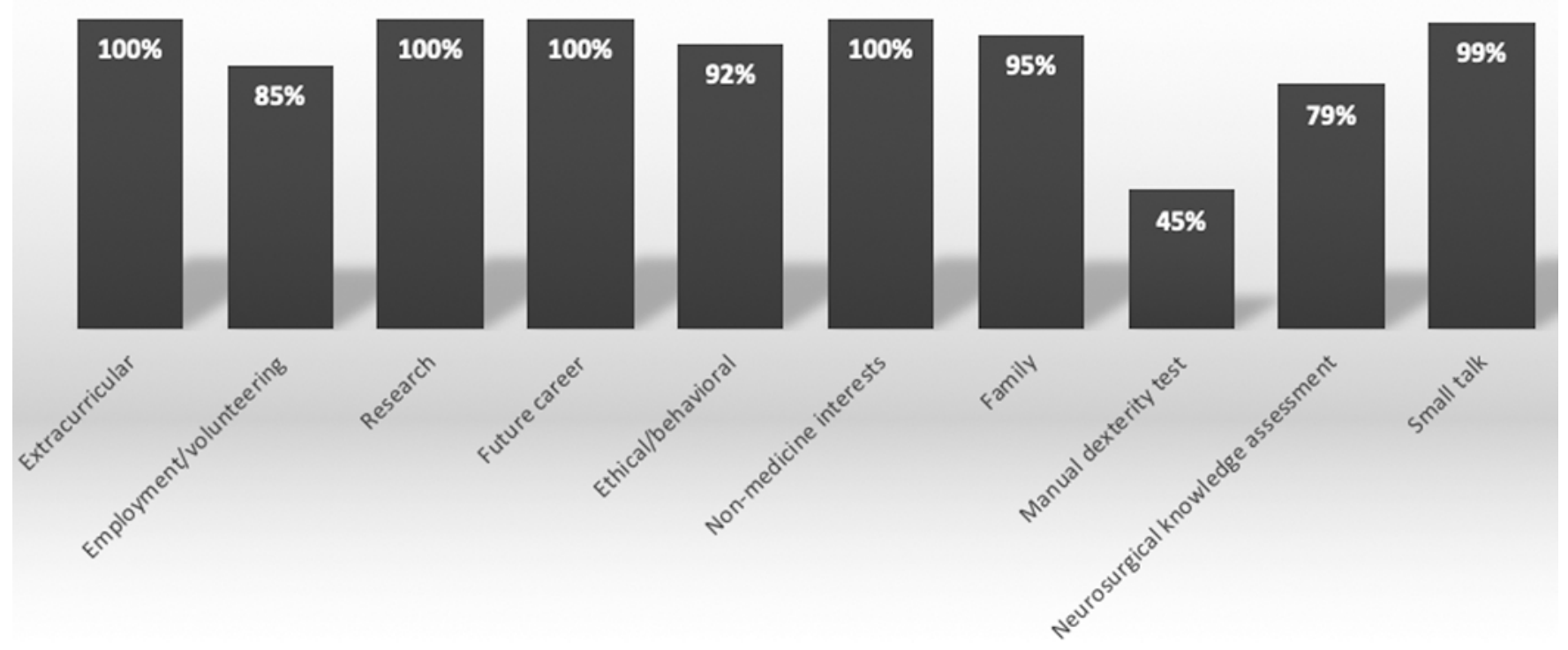

FIG. 1. Percentage of respondents asked about various topics during neurosurgery interviews. 
TABLE 2. Useful/appropriate level and stress/anxiety level of residency interview topics

\begin{tabular}{lcrr}
\hline \multicolumn{1}{c}{ Question Topic } & Useful/Appropriate Level ${ }^{*}$ & Stress/Anxiety Level $\dagger$ & Correlation: Spearman's rho, $p$ Value \\
\hline Extracurricular activities $(n=130)$ & $4.36 \pm 0.69$ & $1.50 \pm 0.76$ & $-0.07,0.42$ \\
\hline Employment/volunteering $(n=130)$ & $4.38 \pm 0.68$ & $1.48 \pm 0.71$ & $-0.08,0.41$ \\
\hline Prior research $(n=130)$ & $4.76 \pm 0.50$ & $2.08 \pm 1.18$ & $-0.08,0.39$ \\
\hline Goals \& objectives of future neurosurgery career $(n=131)$ & $4.78 \pm 0.49$ & $2.15 \pm 1.14$ & $0.06,0.51$ \\
\hline Ethical/behavioral scenarios $(n=131)$ & $3.90 \pm 0.92$ & $2.94 \pm 1.28$ & $-0.12,0.18$ \\
\hline Non-medicine interests/hobbies $(n=131)$ & $4.46 \pm 0.71$ & $1.38 \pm 0.72$ & $-0.16,0.08$ \\
\hline Family $(n=130)$ & $3.51 \pm 0.95$ & $1.66 \pm 0.94$ & $-0.30,<0.01$ \\
\hline Manual dexterity tests $(n=130)$ & $2.95 \pm 1.05$ & $2.91 \pm 1.21$ & $-0.40,<0.01$ \\
\hline Neurosurgical knowledge assessment $(n=131)$ & $2.67 \pm 1.09$ & $3.66 \pm 1.23$ & $-0.36,<0.01$ \\
\hline Small talk $(n=130)$ & $4.1 \pm 0.98$ & $1.53 \pm 0.85$ & $-0.12,0.19$ \\
\hline
\end{tabular}

$\mathrm{n}=$ number of applicants with available data.

Values expressed as the mean \pm standard deviation. Boldface type indicates statistical significance.

* 1 = not useful/appropriate, 2 = somewhat useful/appropriate, 3 = neutral, $4=$ useful/appropriate, 5 = very useful/appropriate.

$\dagger 1=$ no stress/anxiety, $2=$ minimal stress, $3=$ neutral, $4=$ somewhat stressful, $5=$ very stressful.

scenarios (44\%), and surgical manual dexterity tests $(25 \%$; Table 3).

Spearman rank correlation analysis revealed that the variables with the highest correlation between utility and stress were manual dexterity tests $(\mathrm{r}=-0.40, \mathrm{p}<0.01$; Table 2) and neurosurgical knowledge assessment ( $\mathrm{r}=$ $-0.36, \mathrm{p}<0.01$ ), meaning that there was an inverse correlation between least useful and most stressful for these topics. Although ethical/behavioral questions were rated the second most stressful, there was no significant correla- tion between stress and utility for this topic $(r=-0.12, p$ $=0.18$ ). Nevertheless, the mean Likert score for this topic was $3.90 \pm 0.92$, indicating that applicants found utility in such questions despite rating them as stressful.

\section{Who Is More Likely to Find Certain Topics Stressful?}

We assessed which applicant characteristics were associated with rating questions as stressful. All variables with $>5 \%$ stressfulness response (Likert score 4 or 5) were included in the logistic regression analysis of what applicant

\section{Interview question topics found most useful}

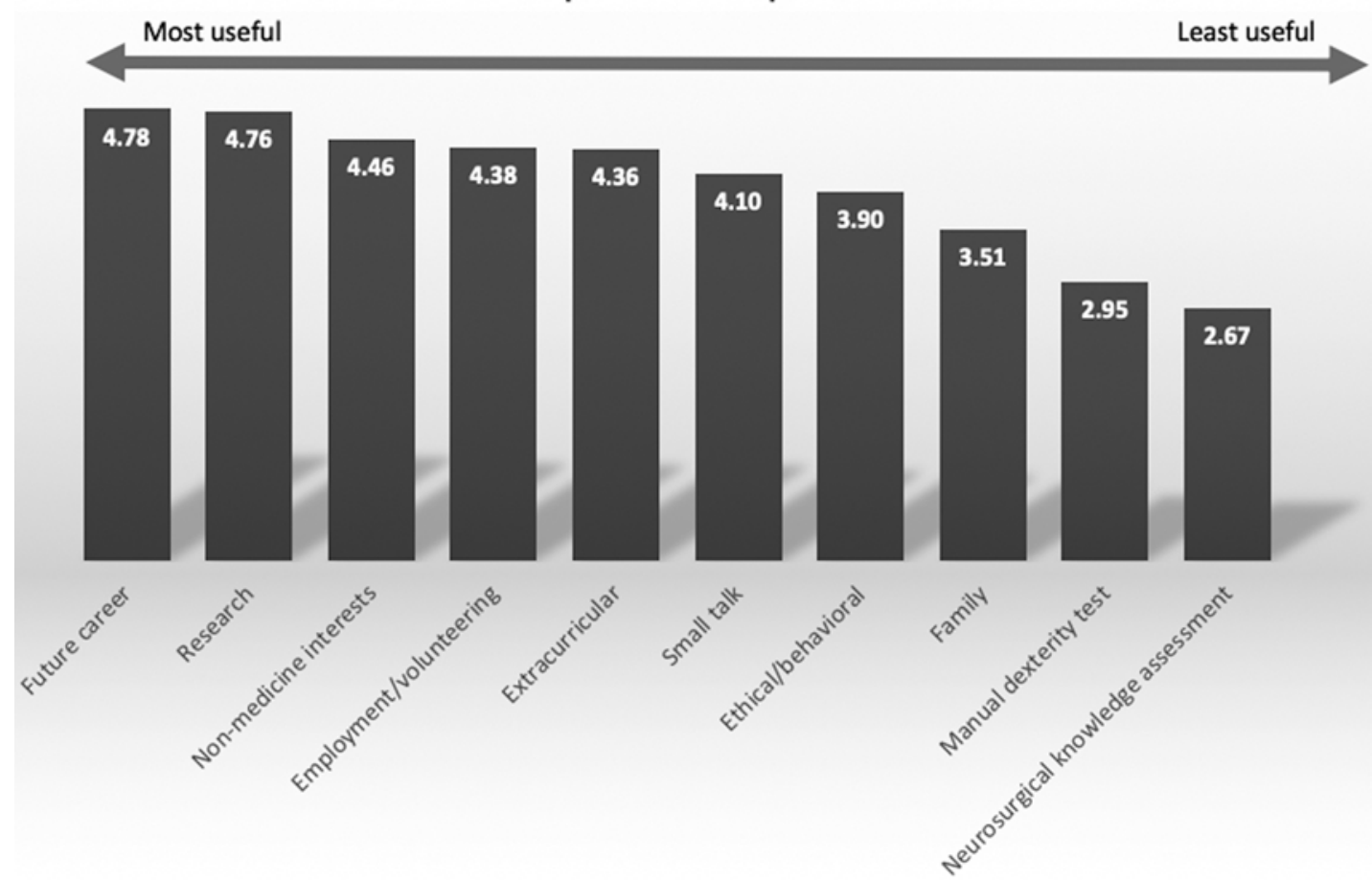

FIG. 2. Ranking of utility of interview question topics. 


\section{Interview question topics found most stressful}

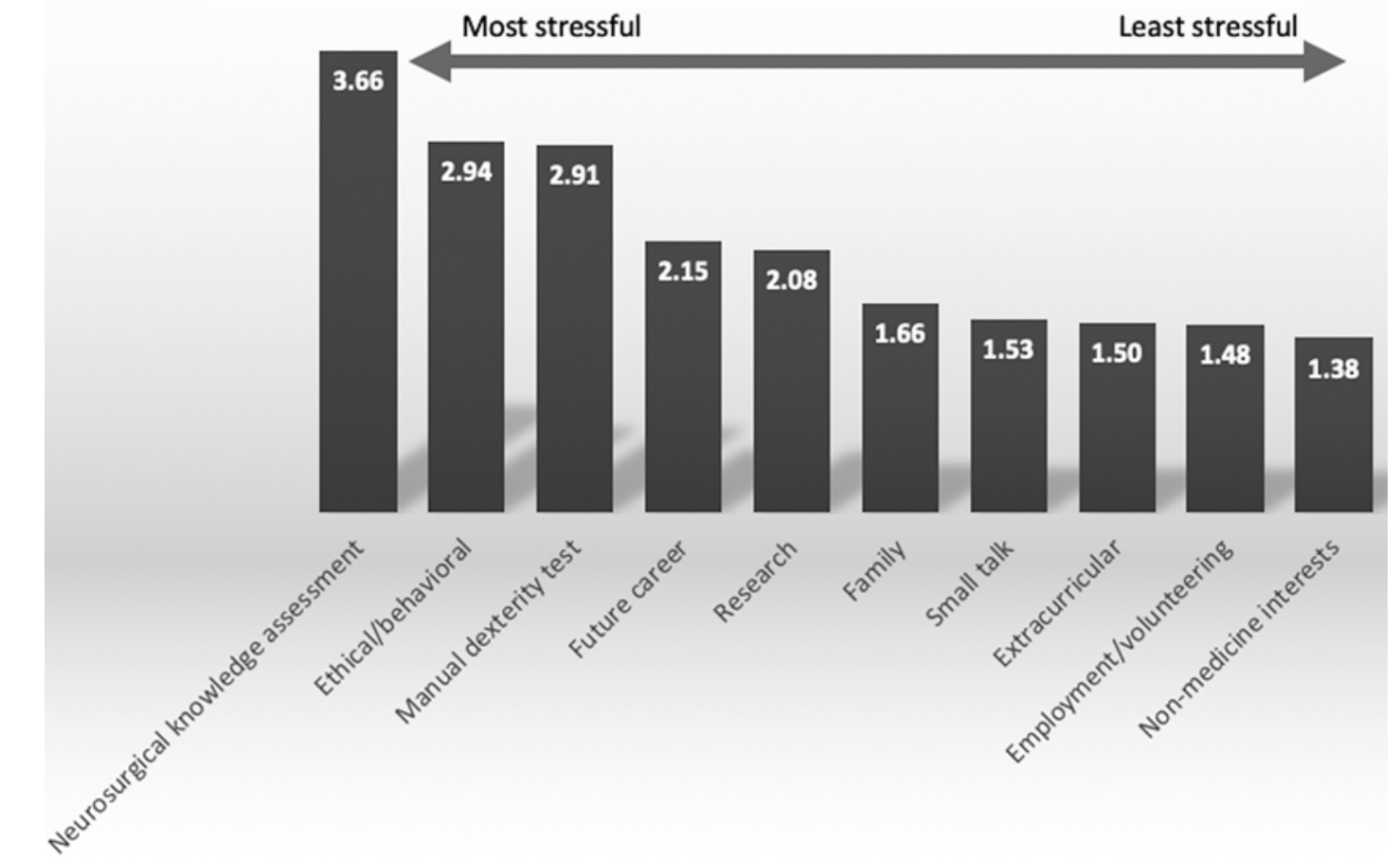

FIG. 3. Ranking of most and least stressful question topics.

characteristics were associated with perceiving questions as more stressful (Table 4). Females had higher odds of finding neurosurgical knowledge assessment questions more stressful than males (OR 6.77, 95\% CI 2.17-21.13, p $<0.01$ ) and applicants whose age was $>30$ years had higher odds of finding family questions more stressful than those who were younger (OR 5.94, 95\% CI 0.97-36.30, $\mathrm{p}=0.05)$.

\section{Who Is More Likely to Be Asked Stressful Questions?}

We also assessed which applicant characteristics were

TABLE 3. Respondents who found question topics stressful

\begin{tabular}{lc}
\hline \multicolumn{1}{c}{ Question Topic } & No. $(\%)$ \\
\hline Prior extracurricular work $(n=122)$ & $2(2)$ \\
\hline Employment/volunteering $(n=122)$ & $0(0)$ \\
\hline Prior research $(n=122)$ & $24(20)$ \\
\hline Goals \& objectives of future neurosurgery career $(n=122)$ & $22(18)$ \\
\hline Ethical/behavioral scenarios $(n=122)$ & $54(44)$ \\
\hline Non-medicine interests/hobbies $(n=122)$ & $3(2)$ \\
\hline Family $(n=121)$ & $7(6)$ \\
\hline Manual dexterity tests $(n=122)$ & $31(25)$ \\
\hline Neurosurgical knowledge assessment $(n=122)$ & $72(59)$ \\
\hline Small talk $(n=121)$ & $4(3)$ \\
\hline
\end{tabular}

$\mathrm{n}=$ number of applicants with available data.

Likert scale scores $1-5$ were collapsed into the binary response categories of $1-3=$ not stressful and $4-5=$ stressful for this assessment. associated with an increased chance of being asked stressful questions. Logistic regression tested which applicants were asked about the three most stressful topics, that is, neurosurgical knowledge assessment, ethical/behavioral scenarios, and manual dexterity tests (Table 5). Overall, few significant associations were found. Applicants who attended $\geq 15$ interviews were more likely to be asked all three questions. Moreover, respondents with children were less likely to be asked ethical/behavioral questions (OR $0.13,95 \%$ CI $0.03-0.52, \mathrm{p}<0.01)$.

\section{Discussion}

We report a multiinstitutional assessment of the incidence, stressfulness, and utility of common topics discussed during neurosurgery residency interviews, all from the applicant's perspective. Using applicant surveys, we identified the three most stressful topics as neurosurgical knowledge assessment, ethical/behavioral scenarios, and manual dexterity tests. Further, the utility and stress associated with questions regarding knowledge assessments and manual dexterity tests were negatively correlated, signifying low utility and high stress. While ethical/behavioral scenarios had no such correlation between utility and stress, their mean Likert scores did indicate that applicants found these questions to be useful despite inducing high stress levels. Applicants interviewing at $\geq 15$ training programs were significantly more likely to be asked questions identified as stressful overall, and applicants with children were less likely to be asked about ethical/behavioral scenarios. Taken together, these data provide an important perspective into the resident applicant experience and 
TABLE 4. Predictors of who is most likely to find each question topic more stressful

\begin{tabular}{|c|c|c|c|c|c|c|}
\hline \multirow[b]{2}{*}{ Predictive Factor } & \multicolumn{6}{|c|}{ OR $(95 \% \mathrm{Cl}), \mathrm{p}$ Value } \\
\hline & $\begin{array}{c}\text { Prior } \\
\text { Research }\end{array}$ & $\begin{array}{l}\text { Goals of } \\
\text { Career }\end{array}$ & $\begin{array}{l}\text { Ethical } \\
\text { Scenarios }\end{array}$ & Family & $\begin{array}{l}\text { Manual Dexterity } \\
\text { Tests }\end{array}$ & $\begin{array}{l}\text { Knowledge } \\
\text { Assessment }\end{array}$ \\
\hline Female sex (vs males) & $\begin{array}{l}0.43(0.15,1.26) \\
\quad 0.125\end{array}$ & $\begin{array}{l}0.87(0.32,2.32) \\
\quad 0.776\end{array}$ & $\begin{array}{l}1.20(0.56,2.58) \\
0.631\end{array}$ & $\begin{array}{l}0.74(0.14,3.98) \\
0.724\end{array}$ & $\begin{array}{l}1.60(0.63,4.04) \\
0.325\end{array}$ & $\begin{array}{l}6.77(2.17,21.13), \\
\quad 0.001\end{array}$ \\
\hline Non-white race (vs white) & $\begin{array}{l}1.87(0.76,4.59) \\
0.174\end{array}$ & $\begin{array}{l}0.96(0.37,2.44) \\
\quad 0.925\end{array}$ & $\begin{array}{l}1.08(0.52,2.26) \\
0.829\end{array}$ & $\begin{array}{l}0.53(0.10,2.82) \\
\quad 0.453\end{array}$ & $\begin{array}{l}1.51(0.60,3.78) \\
0.378\end{array}$ & $\begin{array}{l}0.80(0.35,1.88) \\
\quad 0.580\end{array}$ \\
\hline Foreign born (vs birthplace US) & $\begin{array}{l}1.3(0.46,3.70) \\
\quad 0.623\end{array}$ & $\begin{array}{l}1.99(0.71,5.56) \\
0.189\end{array}$ & $\begin{array}{l}1.02(0.43,2.44) \\
0.964\end{array}$ & $\begin{array}{l}0.57(0.07,4.99) \\
\quad 0.614\end{array}$ & $\begin{array}{l}1.76(0.63,4.92) \\
0.280\end{array}$ & $\begin{array}{l}1.08(0.42,2.81) \\
0.872\end{array}$ \\
\hline Married (vs single) & $\begin{array}{l}0.84(0.26,2.69) \\
\quad 0.767\end{array}$ & $\begin{array}{l}0.71(0.23,2.24) \\
\quad 0.562\end{array}$ & $\begin{array}{l}0.87(0.31,2.39) \\
\quad 0.782\end{array}$ & $\begin{array}{l}0.97(0.13,7.33) \\
\quad 0.973\end{array}$ & $\begin{array}{l}0.61(0.15,2.44) \\
\quad 0.483\end{array}$ & $\begin{array}{l}0.97(0.31,3.02) \\
\quad 0.960\end{array}$ \\
\hline $\begin{array}{l}\text { Raising children (vs not raising } \\
\text { children) }\end{array}$ & $\begin{array}{l}0.80(0.16,3.92) \\
\quad 0.783\end{array}$ & $\begin{array}{l}1.59(0.39,6.45) \\
\quad 0.512\end{array}$ & $\begin{array}{l}1.20(0.33,4.40) \\
0.779\end{array}$ & $\begin{array}{l}1.52(0.17,13.77) \\
0.712\end{array}$ & NA & $\begin{array}{l}1.38(0.34,5.53) \\
0.654\end{array}$ \\
\hline Age $>30$ yrs (vs $\leq 30$ yrs) & $\begin{array}{l}3.72(0.92,15.10) \\
\quad 0.066\end{array}$ & $\begin{array}{l}1.33(0.26,6.88), \\
0.735\end{array}$ & $\begin{array}{l}0.69(0.16,3.05) \\
0.629\end{array}$ & $\begin{array}{l}5.94(0.97,36.30) \\
\quad 0.054\end{array}$ & $\begin{array}{l}0.36(0.04,3.37) \\
\quad 0.369\end{array}$ & $\begin{array}{l}1.55(0.30,8.07) \\
0.606\end{array}$ \\
\hline Attended $\geq 15$ interviews (vs $<15$ ) & $\begin{array}{l}1.5(0.78,1.85) \\
0.399\end{array}$ & $\begin{array}{l}1.00(0.39,2.66), \\
0.879\end{array}$ & $\begin{array}{l}1.24(0.60,2.61) \\
0.569\end{array}$ & $\begin{array}{l}1.77(0.33,9.52) \\
0.506\end{array}$ & $\begin{array}{l}1.95(0.72,5.27) \\
0.187\end{array}$ & $\begin{array}{l}1.13(0.49,2.66), \\
0.778\end{array}$ \\
\hline
\end{tabular}

$\mathrm{NA}=$ not applicable.

Variables with $>5 \%$ stress were selected. Boldface type indicates statistical significance.

highlight a number of avenues for potential standardization and improvement of the interview process.

\section{Key Results and Interpretation}

While three of the six most commonly asked questions were related to professional interests, the other three focused on noncareer topics (non-medicine interests, family, small talk), which may reflect the priority of interviewers to identify well-rounded applicants or individuals whose company they would anticipate enjoying over 7 years. Surprisingly, applicants may have limited insight into this reality, as the subject of non-medicine interests was the only nonprofessional topic rated in the top five for utility. The other four most useful topics from the applicant's perspective were those related to accomplishments and career goals. Applicants should consider topics such as non-medicine interests, family, and small talk just as important to faculty interviewers as accomplishments and career goals, if not more so.

Applicants rated neurosurgical knowledge assessments and manual dexterity tests as the least useful, as well as two of the three most stressful topics. These results agree with those of prior studies, as Long et al. ${ }^{4}$ reported that only $8 \%$ of anesthesia resident applicants supported a knowledge assessment or skills challenge. The significant inverse correlations between utility and stressfulness for knowledge assessments and manual dexterity tests suggest that, according to applicants, the overall value of these questions in the interview process may be marginal. Conversely, although applicants reported ethical/behavioral scenarios to be stressful, the absence of a significant correlation with low utility indicates that these may yet have an important role in the interview process, a concept well recognized by applicants. One potential solution to better prepare applicants is for each institution to conduct mock interviews focusing on these more stressful areas of knowledge assessments, dexterity tests, and ethical/behavioral scenarios. ${ }^{18}$
Importantly, we are not discouraging the use of knowledge assessments or manual dexterity tests based only on the applicant's perspective. In truth, experienced faculty may deem these questions highly useful in predicting performance. That said, we do believe that potentially marked heterogeneity between dexterity tests and how they were administered could have likely contributed to their low utility scores. Indeed, when conducted in an organized, structured fashion, dexterity tests may have a place in recruitment, as demonstrated in a study of otolaryngology applicants by Moore et al. ${ }^{19}$ In their formalized assessment of microsurgical skills, applicant evaluation scores correlated well with future residency performance, specifically the "attitudinal" component of this scale, which was defined as, "perceives as challenge, focused, determined to complete well, focused questions, not distracted." 19 Further development of strategies to evaluate these traits in a fair, structured manner may improve both applicants' perceptions of such questions and their value to assessors. Furthermore, the opinion of experienced faculty on these more stressful areas is to be valued, and an attempt to ask these challenging questions in a standardized, equal, professional manner represents the optimal form of questioning.

Essentially no significant associations were noted between candidate features and the likelihood of being asked questions rated as stressful. One noteworthy exception is the relationship between a higher number of interviews attended ( $\geq 15$ ) and being asked the three most stressful questions - a finding that most likely reflects a simple increase in exposure. Another curious finding was the association between an applicant's status as a parent and the decreased likelihood of being asked ethical/behavioral questions. Although we can only speculate as to the interpretation of this finding, the fact that many interviewing neurosurgeons are parents themselves may indicate a higher degree of assumed ethical alignment with candi- 
TABLE 5. Logistic regression: predictors of who is more likely to be asked the three most stressful questions

\begin{tabular}{ll}
\hline \multicolumn{1}{c}{ Questions \& Categories } & OR $(95 \% \mathrm{Cl}), \mathrm{p}$ Value \\
\hline $\begin{array}{l}\text { Were you more likely to be asked about } \\
\text { neurosurgical knowledge assessment? }\end{array}$ & \\
\hline Female & $1.15(0.46,2.91), 0.761$ \\
\hline Non-white & $0.99(0.42,2.33), 0.973$ \\
\hline Foreign born & $0.94(0.34,2.61), 0.904$ \\
\hline Married & $0.53(0.14,2.03), 0.353$ \\
\hline Children & $0.76(0.19,3.02), 0.694$ \\
\hline Age $>30$ yrs & $0.90(0.18,4.61), 0.901$ \\
\hline Attended $\geq 15$ interviews & $3.62(1.48,8.87), 0.005$ \\
\hline Were you more likely to be asked about & \\
ethical/behavioral scenarios? & \\
\hline Female & $1.28(0.32,5.11), 0.723$ \\
\hline Non-white & $0.80(0.23,2.77), 0.725$ \\
\hline Foreign-born & $0.70(0.17,2.84), 0.620$ \\
\hline Married & $0.37(0.07,2.08), 0.261$ \\
\hline Children & $0.125(0.03,0.52), 0.004$ \\
\hline Age $>30$ yrs & $0.28(0.05,1.54), 0.144$ \\
\hline Attended $\geq 15$ interviews & $7.24(1.50,35.00), 0.014$ \\
\hline Were you more likely to be asked about & \\
manual dexterity tests? & $1.63(0.77,3.43), 0.200$ \\
\hline Female & $1.36(0.67,2.76), 0.389$ \\
\hline Non-white & $1.39(0.59,3.25), 0.449$ \\
\hline Foreign-born & $0.53(0.19,1.45), 0.213$ \\
\hline Married & $0.37(0.10,1.43), 0.150$ \\
\hline Children & $0.16(0.02,1.32), 0.088$ \\
\hline Age $>30$ yrs & $3.09(1.48,6.48), 0.003$ \\
\hline
\end{tabular}

The three most stressful question topics were surgical skills/dexterity tests, ethical/behavioral scenarios, or neurosurgical knowledge assessment. Boldface type indicates statistical significance.

dates who also have children. An assessment of relationships between applicant features and their individual likelihood of rating questions as stressful did indicate female sex as being associated with an increased likelihood of reporting neurosurgical knowledge assessments as stressful, whereas older applicants were more likely to rate questions about family as stressful. Although the current study confirms that these same applicant groups were not specifically targeted by interviewers and asked stressful questions at a higher incidence, this finding nevertheless emphasizes an important potential niche for making the interview process more enjoyable.

\section{A Case for Standardization and Structure}

While the present study did not specifically assess a structured interview format, when combined with evidence from the literature, our results suggest that providing more structure and standardization to the interview process may benefit applicants and programs alike. Several key strategies that have been successfully validated in comparative settings warrant consideration in formulating recommendations for the neurosurgery resident interview process.

Perhaps the most notable approach is the behavioral interview, which offers an organized mechanism for generating and presenting substantial interview questions. Tatem and colleagues ${ }^{20}$ implemented a behavior-based interview structure to the pulmonary and critical care fellowship process, in which faculty members attended two workshops and defined "best fit" criteria, identified behavioral questions that fit these criteria, and practiced mock interviews. The authors positively concluded that this pilot process achieved consensus among faculty on sought-after traits for incoming fellows. Breitkopf et al..$^{21}$ asked standardized, behavioral questions to 104 obstetrics and gynecology resident applicants over 3 years, which provided objective, concrete data: applicants with an older age and prior employment demonstrated superior leadership, coping, and conflict management. It is no secret that evaluators like to rely on concrete, numerical metrics, of which exam scores represent the most objective data. However, United States Medical Licensing Examination (USMLE) Step 1 scores have been shown to have little utility in predicting academic positions, academic rank, and $\mathrm{h}$ index. ${ }^{22} \mathrm{The}$ extent to which we can make a subjective process as objective as possible, with scores from a behavioral, structured interview, the less reliant we can be on poor predictors and the more reliant on reliable, evidence-based methods.

Another important aspect of improving applicant interviews is education of the involved staff. Among general surgeons, Gardner et al. ${ }^{6}$ showed that the implementation of a half-day course on conducting structured interviews, asking fair questions, and rating applicants led to improved faculty agreement, with $80 \%$ of ratings within 2 points of each other. It should not be assumed that evaluators have an innate, intuitive ability to interview well; as with any new skill, education is integral to new interview techniques.

Although the findings of the current study are preliminary, they provide compelling evidence that programs should consider a more standardized approach to conducting interviews - a practice that is presently reported in only $5 \%$ of general surgery programs and potentially even fewer in neurosurgery. ${ }^{17}$ Correspondingly, we anticipate that the following information, although not yet formally validated, may provide a useful framework for departments to discuss, analyze, and standardize their own processes (Table 6). We recommend that future studies of residency applicants delve into whether applicants understand and appreciate the rationale behind stressful questions and how this understanding or lack thereof affects their opinion of the interviewer and program. Armed with an improved understanding of the interview, programs can begin to use extra-interview data in combination with personality assessments to further tap into an applicant's character in a standardized manner. ${ }^{23}$

The current study is subject to a variety of limitations, including all those associated with survey data, small sample sizes, and recall bias. Perhaps the most important study-specific limitation is our focus on the applicants themselves, without conducting a corollary assessment of the interviewing staff and their impressions regarding 
TABLE 6. Proposed framework to standardize the residency interview process

\begin{tabular}{|c|c|c|}
\hline $\begin{array}{l}\text { Area for } \\
\text { Improvement }\end{array}$ & Example Implementation & Detailed Discussion \\
\hline $\begin{array}{l}\text { Behavioral ques- } \\
\text { tions }\end{array}$ & $\begin{array}{l}\text { Consider } 4-6 \text { behavioral questions that } \\
\text { are asked of all applicants \& that can be } \\
\text { objectively scored }\end{array}$ & $\begin{array}{l}\text { Evidence-based practice for generating objective \& useful interview questions } \\
\text { can be dictated by department-specific, prespecified "ideal applicant factors" \& } \\
\text { "essential behaviors for success"; attempts can be made to ensure that all ap- } \\
\text { plicants answer the same questions \& are scored on a question-specific rubric }\end{array}$ \\
\hline $\begin{array}{l}\text { Interviewer } \\
\text { education }\end{array}$ & $\begin{array}{l}\text { Encourage workshops, courses, or webi- } \\
\text { nars for interviewing faculty }\end{array}$ & $\begin{array}{l}\text { Formal training sessions can provide a validated, high-yield, low-stakes opportunity } \\
\text { to improve faculty awareness of key aspects of professionalism, unconscious } \\
\text { bias, vulnerable populations, standardized interviewing techniques, illegal ques- } \\
\text { tions, \& related topics }\end{array}$ \\
\hline $\begin{array}{l}\text { Interviewer } \\
\text { preparation }\end{array}$ & $\begin{array}{l}\text { Conduct mock interviews for faculty to } \\
\text { improve standardization }\end{array}$ & $\begin{array}{l}\text { Deliberate practice can ensure that new tools \& techniques are trialed \& refined out- } \\
\text { side of the formal interview setting \& necessary interviewer feedback is provided }\end{array}$ \\
\hline $\begin{array}{l}\text { Ensuring con- } \\
\text { sistency of high- } \\
\text { stress questions }\end{array}$ & $\begin{array}{l}\text { As deemed useful by experienced faculty, } \\
\text { knowledge assessments \&/or manual } \\
\text { dexterity tests should be administered \& } \\
\text { graded in objective, standardized fashion }\end{array}$ & $\begin{array}{l}\text { Stressful questions can be very useful \& are encouraged as each department } \\
\text { deems fit, yet these domains should ideally be incorporated only w/ validated } \\
\text { techniques, such as the microsurgical assessment reported by Moore et al., } \\
2015,,^{9} \& \text { other objective, transparent metrics }\end{array}$ \\
\hline $\begin{array}{l}\text { Process trans- } \\
\text { parency }\end{array}$ & $\begin{array}{l}\text { Consider providing applicants w/ advanced } \\
\text { information of challenging aspects of } \\
\text { interview experience }\end{array}$ & $\begin{array}{l}\text { To mitigate undue stress, programs can consider emailing applicants before the } \\
\text { interview to explain format, rationale, \& structure of each interview, which may } \\
\text { decrease perceived stressfulness \& increase perceived utility w/o sacrificing util- } \\
\text { ity of performance under stress gleaned by each interviewer }\end{array}$ \\
\hline
\end{tabular}

the stress level or utility associated with various domains. There are challenges throughout both the interview process and residency that are stressful and can seem to have questionable utility at the time, with the applicant or resident only later realizing the benefit of such an encounter. By having only one perspective - the applicant and not the faculty-these results do not provide any potential insight gained after enduring the stressful experience. This highlights an important avenue for future study, especially as more programs gravitate toward a standardized interview format. Additional considerations include the inability of a cross-sectional study design to provide insights regarding causal and temporal relationships in the data, discrepancies between self-reported impressions among responders and true preferences among all pertinent applicants, and study reliance on relatively weak statistical methods, such as correlation testing. Moreover, we did not present operational definitions of each of the question types and instead left this to the discretion of the respondent. It is entirely possible that applicants had varying definitions of what constituted each question topic, which may have invalidated some results. Applicant demographic data were also missing, which prevented us from further studying what types of applicants had certain perceptions regarding the interview. Additionally, interviews are one part of an applicant's package, which includes a lengthy personal statement. The personal statement likely conveyed much of the information discussed during the interview, which may have led applicants to rate these areas as less stressful given their familiarity with the information. The current study was also limited by having only multiplechoice questions, and future studies should consider using free-text or qualitative responses to better understand the nuanced opinions of applicants. Lastly, these data were obtained from applicants who had applied to one of three programs, and we do not know if they interviewed at each program or how that may have affected survey responses. Despite these shortcomings, the present analysis is unique in the neurosurgical literature and, we hope, will provide a number of useful insights regarding improvements to the interview process, as well as key areas for further study.

\section{Conclusions}

Neurosurgery is a highly competitive specialty, and resident applicant selection and interview techniques are a heterogeneous process. Although essentially all programs heavily weigh the interview process within their decisionmaking schema, very few programs have adopted the standardized techniques demonstrated in parallel fields, which may synthesize evaluator assessment and improve satisfaction with the process among interviewers and applicants alike. As awareness of issues such as unconscious bias continues to expand and the utility of traditional metrics such as USMLE Step 1 scores are increasingly understood to be poor predictors of clinical performance, the need for a more rigorous and formal study approach to applicant interviewing and selection will become unambiguous. We recommend that neurosurgery programs begin to discuss and integrate measures to improve objectivity and reduce bias in order to limit our shared reliance on poor predictors and elevate the role played by reliable, evidence-based metrics in substantiating this key aspect of neurosurgery resident selection.

\section{References}

1. Makdisi G, Takeuchi T, Rodriguez J, et al. How we select our residents - a survey of selection criteria in general surgery residents. J Surg Educ. 2011;68(1):67-72.

2. Smilen SW, Funai EF, Bianco AT. Residency selection: should interviewers be given applicants' board scores? Am J Obstet Gynecol. 2001;184(3):508-513. 
3. Deloney LA, Perrot LJ, Lensing SY, Jambhekar K. Radiology resident recruitment: a study of the impact of web-based information and interview day activities. Acad Radiol. 2014; 21(7):931-937.

4. Long T, Dodd S, Licatino L, Rose S. Factors important to anesthesiology residency applicants during recruitment. $J$ Educ Perioper Med. 2017;19(2):E604.

5. Schneeweiss R, Bergman J, Clayton J. Characteristics of the residency interview process preferred by medical student applicants. J Fam Pract. 1982;15(4):669-672.

6. Gardner AK, D’Onofrio BC, Dunkin BJ. Can we get faculty interviewers on the same page? An examination of a structured interview course for surgeons. J Surg Educ. 2018;75(1): 72-77.

7. Hern HG Jr, Alter HJ, Wills CP, et al. How prevalent are potentially illegal questions during residency interviews? Acad Med. 2013;88(8):1116-1121.

8. Gardner AK, Grantcharov T, Dunkin BJ. The science of selection: using best practices from industry to improve success in surgery training. J Surg Educ. 2018;75(2):278-285.

9. Oyler J, Thompson K, Arora VM, et al. Faculty characteristics affect interview scores during residency recruitment. Am J Med. 2015;128(5):545-550.

10. Brummond A, Sefcik S, Halvorsen AJ, et al. Resident recruitment costs: a national survey of internal medicine program directors. Am J Med. 2013;126(7):646-653.

11. Agarwal N, Choi PA, Okonkwo DO, et al. Financial burden associated with the residency match in neurological surgery. J Neurosurg. 2017;126(1):184-190.

12. Wood JS, David LR. Outcome analysis of factors impacting the plastic surgery match. Ann Plast Surg. 2010;64(6): 770-774.

13. Joshi ART, Vargo D, Mathis A, et al. Surgical residency recruitment-opportunities for improvement. J Surg Educ. 2016;73(6):e104-e110.

14. Residency applicants from U.S. MD-granting medical schools to ACGME-accredited programs by specialty and sex, 2019-2020. Association of American Medical Colleges. Accessed May 4, 2020. https://www.aamc.org/system/ files/2019-12/2019_FACTS_Table_C-2.pdf

15. Camp CL, Sousa PL, Hanssen AD, et al. Orthopedic surgery applicants: what they want in an interview and how they are influenced by post-interview contact. J Surg Educ. 2016; 73(4):709-714.

16. Hern HG Jr, Johnson B, Alter HJ, et al. Asking for a commitment: violations during the 2007 match and the effect on applicant rank lists. West J Emerg Med. 2015;16(2):331-335.

17. Kim RH, Gilbert T, Suh S, et al. General surgery residency interviews: are we following best practices? Am J Surg. 2016; 211(2):476-481.e3.

18. Klammer RM, Haydel MJ, Gallahue F, et al. Program visits and residency interviews. J Emerg Med. 2019;57(4):e133e139.
19. Moore EJ, Price DL, Van Abel KM, Carlson ML. Still under the microscope: can a surgical aptitude test predict otolaryngology resident performance? Laryngoscope. 2015;125(2): E57-E61.

20. Tatem G, Kokas M, Smith CL, DiGiovine B. A feasibility assessment of behavioral-based interviewing to improve candidate selection for a pulmonary and critical care medicine fellowship program. Ann Am Thorac Soc. 2017;14(4): 576-583.

21. Breitkopf DM, Vaughan LE, Hopkins MR. Correlation of behavioral interviewing performance with obstetrics and gynecology residency applicant characteristics. J Surg Educ. 2016;73(6):954-958.

22. Gelinne A, Zuckerman S, Benzil D, et al. United States Medical Licensing Exam Step I score as a predictor of neurosurgical career beyond residency. Neurosurgery. 2019;84(5): 1028-1034.

23. Lubelski D, Healy AT, Friedman A, et al. Correlation of personality assessments with standard selection criteria for neurosurgical residency applicants. J Neurosurg. 2016;125(4): 986-994.

\section{Disclosures}

Dr. Chambless is a consultant for Stryker. Dr. Chitale has received clinical or research support from Medtronic, Cerenovus, and Microvention for the study described.

\section{Author Contributions}

Conception and design: Zuckerman, Limoges, Mocco. Acquisition of data: Zuckerman, Limoges, Yengo-Kahn, Mocco. Analysis and interpretation of data: Zuckerman. Drafting the article: Zuckerman, Yengo-Kahn, Graffeo. Critically revising the article: all authors. Reviewed submitted version of manuscript: all authors. Approved the final version of the manuscript on behalf of all authors: Zuckerman. Statistical analysis: Zuckerman, Yengo-Kahn, Mocco. Administrative/technical/material support: Mocco. Study supervision: Chambless, Chitale, Mocco, Durham.

\section{Supplemental Information \\ Online-Only Content}

Supplemental material is available with the online version of the article.

Appendix 1. https://thejns.org/doi/suppl/10.3171/2020.4. JNS2046.

\section{Correspondence}

Scott L. Zuckerman: Vanderbilt University Medical Center, Nashville, TN.zuckerman.scott@gmail.com. 